\title{
EDITORIAL
}

\section{Pulmonary infections: what to do when it's a bug that you do not know}

\author{
M. Woodhead*, A. Ortqvist ${ }^{\#}$
}

Infectious diseases are making a comeback, both in the lung and elsewhere. The reasons for this are diverse and range from changes in the causative bugs to changes in human habits. Infections in the lung have always been important, both because they are very common and because they have a high morbidity and mortality. Community-acquired pneumonia occurs at a rate of one per 1,000 of the adult population, which means that some 300,000 cases occur every year in Eurozone countries. European studies suggest a mortality of $\sim 7 \%$ for those admitted to hospital, rising to nearly $50 \%$ for those that reach the intensive care unit (ICU). Correct antibiotic therapy for the causative organism is therefore important. In most countries, a patient presenting with a severe lower respiratory tract infection will be treated with one or more antibiotics. The most important principle on which this approach is based is that there is one or more known bacterial agents that commonly cause that illness pattern and that the antibiotics prescribed are active against those organisms.

When the patient with a lower respiratory tract infection fails to respond to the given antibiotic treatment a number of questions arise. An important consideration is that the cause of the infection might be a nonbacterial agent or a microbial organism that only rarely causes such infection. This could be an organism that is globally uncommon or a microbial organism that, while common in other parts of the world, is uncommon in that locality. The increase in world travel makes the latter an increasingly common occurrence. Most of us in clinical practice will have encountered this clinical scenario from time to time.
In such a situation, local experience of the management of illness caused by such an organism may be vital, but at the same time hard to find. What would you do when your patient is found to have Francisella tularensis or Echinococcus granulosus, for example? The good news is that by the time you have read the new series in the European Respiratory Journal entitled "Unusual pulmonary infections" you will know what to do and will also know about a range of other unusual causes of lower respiratory tract infection.

It is against this background that this series of articles has been put together. The potential list of organisms to consider is very long, so the following articles cover a personal selection of these, including both locally and globally uncommon infections. We have been fortunate to be able to call on acknowledged experts from around the world to contribute papers. The following topics will be covered: tularaemia, actinomycosis, melioidosis, varicella, Q fever, and echinococcosis.

The first paper in the series describes tularaemia [1]. It is hoped that this and the other papers in the series will inform the general reader, help in the management of some patients and, in some cases, perhaps allow the early recognition of illness caused by an unusual organism.

\section{Reference}

1. Tärnvik A, Berglund L. Tularaemia. Eur Respir $J$ 2003; 21: 361-373.
*Dept of Respiratory Medicine, Manchester Royal Infirmary, Manchester, UK. "Dept of Communicable Disease, Smittskyddsenheten, Stockholm, Sweden.

Correspondence: M. Woodhead, Dept of Respiratory Medicine, Manchester Royal Infirmary, Oxford Road, Manchester, M13 9WL, UK. Fax: 44 1612764989. E-mail: Woodhead@central.cmht.nwest. nhs.uk 